\title{
Evaluation of histopathology of endometrium in primary infertile women, a prospective five years observational study in Konaseema region of Andhra Pradesh
}

\author{
Annapurna P., Niharika Pattnaik* \\ Department of Pathology Konaseema Institute of Medical Science, Amalapuram, Andhra Pradesh, India \\ Received: 05 January 2022 \\ Accepted: 31 January 2022

\section{*Correspondence:} \\ Dr. Niharika Pattnaik, \\ E-mail: pattnaikniharika@gmail.com
}

Copyright: () the author(s), publisher and licensee Medip Academy. This is an open-access article distributed under the terms of the Creative Commons Attribution Non-Commercial License, which permits unrestricted non-commercial use, distribution, and reproduction in any medium, provided the original work is properly cited.

\begin{abstract}
Background: Histopathology of endometrium is considered important investigation in case of infertility. The functional disturbance involved in infertility may result in morphological changes in endometrium. Endometrial histopathology is helpful in dating of endometrium so that hormonal status, ovulation and infertility.

Methods: The material for this study consists of endometrial tissue obtained from patients. It was collected either by endometrial biopsy or curettage of uterus done in the minor OT department of obstetrics and gynaecology. The specimen was processed paraffin tissue processing and section of five micrometer was cut and stained with hematoxylin and eosin and $\mathrm{ZN}$ staining as per requirement.

Results: Morphological and histopathological pattern of endometrium of patients with primary infertility, anovulatory (proliferative endometrium was present in $24(30 \%)$ patients, simple hyperplasia was present in $16(20 \%)$, deficient secretary phase was present in $26(32.50 \%)$ patients, adequate secretary phase was present in $7(8.75 \%)$ patients. Endometrial tuberculosis was diagnosed in $4(5 \%)$ patients and in one patient neoplastic change was found. Arias Stella reaction was present in $1(1.25 \%)$ patients.

Conclusions: From present study we can conclude that the mean age of patients with primary infertility was $25.76 \pm 3.21$ years and most of the patients were between 26 to 35 years of age. Regular menstrual cycle was present in $54(67.5 \%)$ patients and $32.5 \%$ patients were presented with irregular cycle. The duration of infertility between 3 to 6 years was present in $34(42.5 \%)$ patients. Secretory endometrium was present in $52.5 \%$ patients and was most common finding followed by proliferative endometrium. Endometrial tuberculosis was present in $2.5 \%$ patients.
\end{abstract}

Keywords: Primary infertile, Endometrium, Histopathology

\section{INTRODUCTION}

The implantation is dynamic process between blastocyst and endometrium for which priming of endometrium is mandatory so that endometrium will be receptive. ${ }^{1}$ Infertility is a global health issue affecting millions of people of reproductive age worldwide. World health organisation data suggests that available data suggests that between 48 million couples and 186 million individuals have infertility globally. In the female reproductive system, infertility may be caused by a range of abnormalities of the ovaries, uterus, fallopian tubes, and the endocrine system, among others. Infertility can be primary or secondary. Primary infertility is when a pregnancy has never been achieved by a person, and secondary infertility is when at least one prior pregnancy has been achieved. ${ }^{2}$ As per national health portal of India the overall prevalence of infertility in India is between 
3.9 to $16.8 \%$. Prevalence of infertility in Andhra Pradesh is $5 \% .^{3}$ Histopathology of endometrium is considered important investigation in case of infertility. The functional disturbance involved in infertility may result in morphological changes in endometrium. In addition to other newer more recent diagnostic procedures evaluation of endometrial reaction $\mathrm{n}$ infertility is oldest and sensitive indicator of ovulation. ${ }^{4,5}$ Endometrial histopathology is helpful in dating of endometrium so that hormonal status, ovulation and infertility. From literature search we have observed that studies are available about the spectrum of morphological pattern of endometrium in infertile women with variability. Zawar et al has concluded that anovulatory infertility was present in $28.2 \%$ cases. Luteal phase defect was seen in $20 \%$ cases. According to Sahmay et al cystoglandular hyperplasia was seen in $1.7 \%$ cases and tuberculous endometritis was present in $2.6 \%$ cases. $^{6}$ Endometrial biopsy not only shows the hormonal response of endometrium but gives additional information about the local factors of endometrium concerning atrophy, specific and non-specific infections, and malignancy. ${ }^{7}$ Based on above literature finding we have taken opportunity to evaluate the histopathology of endometrium in primary infertile women in Konaseema institute of medical science Amalapuram with objective to categorize and evaluate the histopathological features of endometrium in primary infertility.

\section{METHODS}

This prospective randomized observational crosssectional study conducted in the department of pathology Konaseema institute of medical science Amalapuram from November 2016 to October 2021.

\section{Study population}

The study population include 80 untreated patients who attended the infertility clinic in outpatient department of obstetrics with primary infertility as defined by world health organisation. They have been selected for this study randomly based on inclusion and exclusion criteria.

\section{Inclusion and exclusion criteria}

Inclusion criteria for current study were; all ages, primary infertility and all duration. Exclusion criteria for current study were; secondary infertility, malignancy and known metabolic disorder.

\section{Procedure}

A written informed consent was taken from women before enrolment into this study. After enrolment of patients as per exclusion and inclusion criteria, detailed history was taken and clinical examination of patients was done. The material for this study consists of endometrial tissue obtained from patients. It was collected either by endometrial biopsy or curettage of uterus done in the minor OT department of obstetrics and gynaecology. The specimen was processed paraffin tissue processing and section of five micrometer was cut and stained with Hematoxylin and Eosin (H\&E) and ZN staining as per requirement.

\section{Sample size}

Based on prevalence of infertility to be $5 \%$ in Andhra Pradesh, level of confidence interval $95 \%$ and precision of $5 \%$ sample size was calculated to be 73 by using online calculator. ${ }^{8}$

\section{Statistical analysis}

Data obtained was entered into SPSS 16.0 software and data was analysed as mean and percentage.

\section{RESULTS}

As per selection criteria 80 patients with primary infertility were enrolled for this study. Mean age of patients with primary infertility was $25.76 \pm 3.21$ years. Number of patients having age less than 25 years were 10 (12.5\%), between 26 to 35 years were $44(55 \%)$ and above 35 years were 26 (32.5\%) as depicted in (Table 1). Regarding pattern of menstruation, oligomenorrhea was present in $8(10 \%)$ patients and polymenorrhea was present in $4(5 \%)$ patients. Regular menstrual cycle was present in $54(67.5 \%)$ patients and $32.5 \%$ patients were presented with irregular cycle.

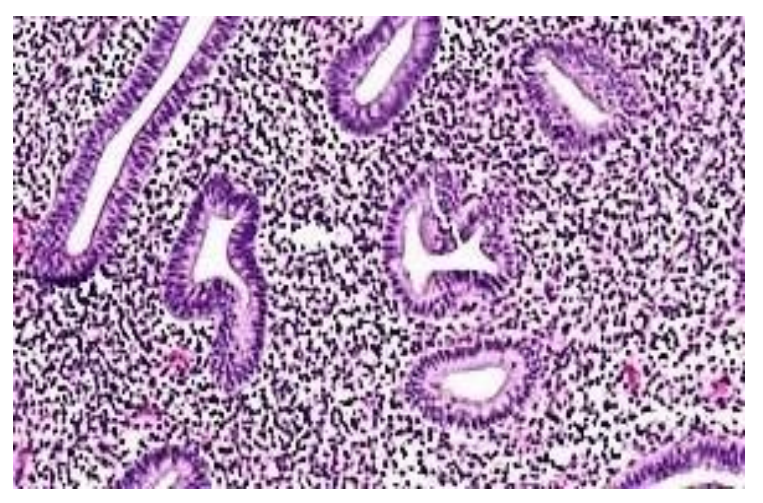

Figure 1: Anovulatory (proliferative).

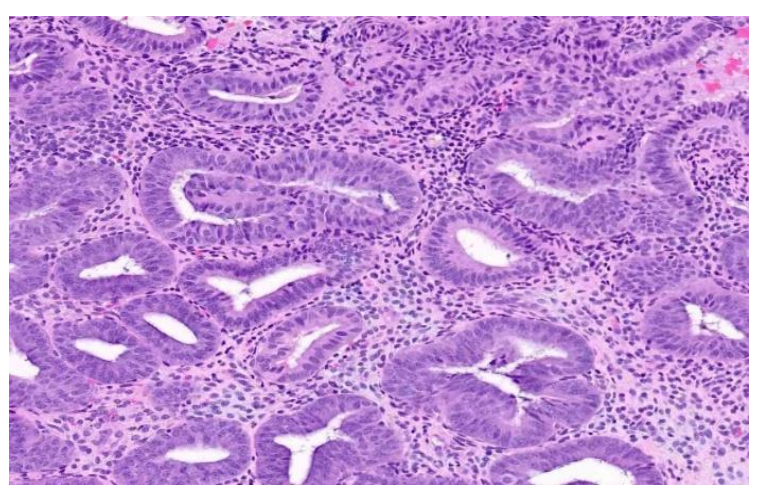

Figure 2: Simple hyperplasia. 
Regarding duration of infertility, 32 (40\%) patients have duration of infertility less than 3 years. Duration of infertility between 3 to 6 years was present in 34 (42.5\%) patients and $14(17.5 \%)$ patients have duration infertility more than 6 years. In present study as per (Table 2), most of the patients $(82.5 \%)$ have no gynaecological complication. PCOS was present in $9(11.25 \%)$ patients, fibroid was present in $3(3.75 \%)$ patients, polyp was present in $1(1.25 \%)$ patients and neoplasm was present in $1(1.25 \%)$. Morphological and histopathological pattern of endometrium of patients with primary infertility, anovulatory (proliferative endometrium was present in $24(30 \%)$ patients, simple hyperplasia was present in $16(20 \%)$, deficient secretary phase was present in $26(32.50 \%)$ patients, adequate secretary phase was present in $7(8.75 \%)$ patients. Endometrial tuberculosis was diagnosed in $4(5 \%)$ patients and in one patient neoplastic change was found. Arias Stella reaction was present in $1(1.25 \%)$ patients.

Table 1: Clinicodemographic profile of study population.

\begin{tabular}{|c|c|c|c|c|}
\hline Variable & & & $\mathbf{N}$ & $\%$ \\
\hline \multirow{3}{*}{ Age $($ years $)($ mean $=25.76 \pm 3.21)$} & \multicolumn{2}{|l|}{ Less than 25} & 10 & 12.5 \\
\hline & \multicolumn{2}{|l|}{26 to 35} & 44 & 55 \\
\hline & \multicolumn{2}{|l|}{ More than 35} & 26 & 32.5 \\
\hline \multirow{5}{*}{ Pattern of menstruation } & \multirow{3}{*}{ Amount of flow } & Oligomenorrhea & 8 & 10 \\
\hline & & Polymenorrhea & 4 & 5 \\
\hline & & Menorrhagia & 2 & 2.5 \\
\hline & \multirow{2}{*}{ Cycle } & Regular & 54 & 67.5 \\
\hline & & Irregular & 26 & 32.5 \\
\hline \multirow{3}{*}{\multicolumn{2}{|c|}{ Duration of infertility (years) }} & Less than 3 & 32 & 40 \\
\hline & & 3 to 6 & 34 & 42.5 \\
\hline & & More than 6 & 14 & 17.5 \\
\hline
\end{tabular}

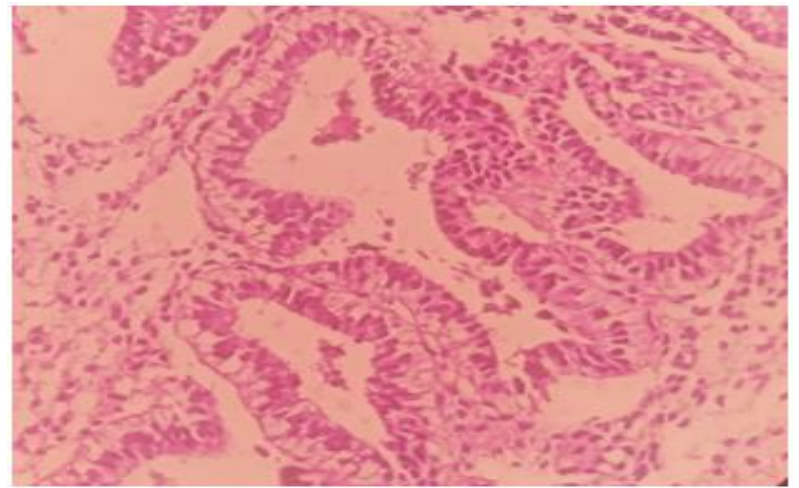

Figure 3: Secretory endometrium.

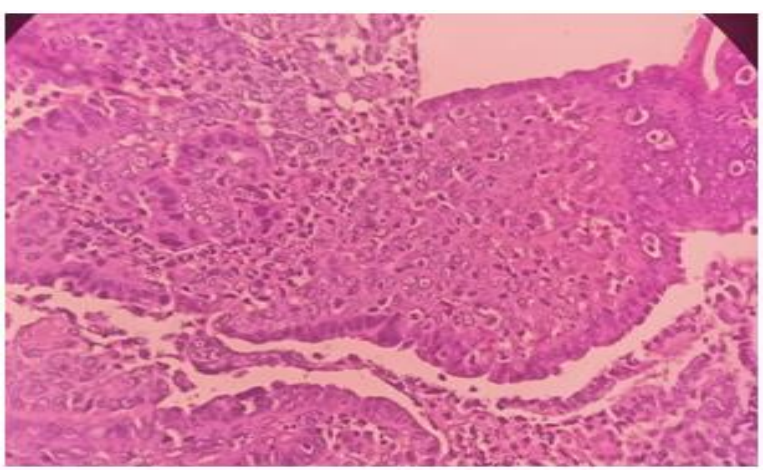

Figure 4: Arias stella reaction.

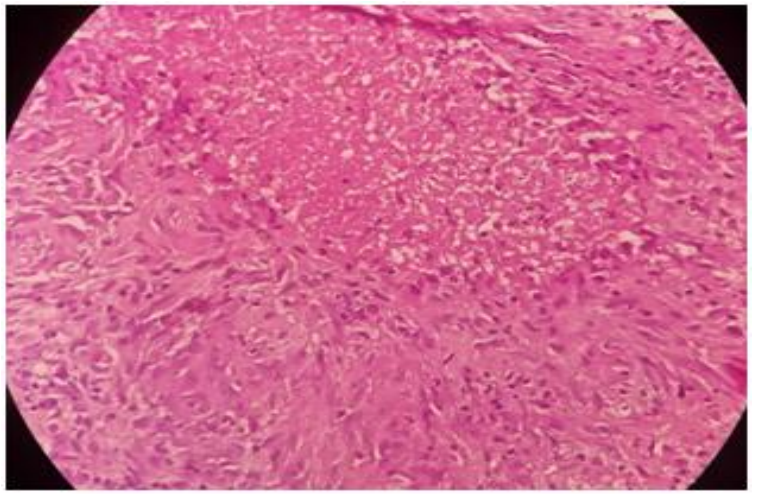

Figure 5: Tubercular endometrium granuloma.

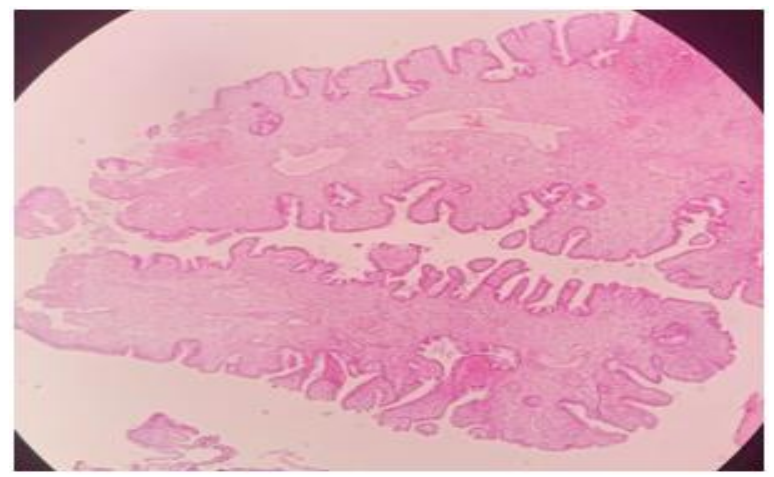

Figure 6: Endometrial polyp. 
Table 2: Gynaecological complication associated with primary infertility patients.

\begin{tabular}{|lll|}
\hline $\begin{array}{l}\text { Associated gynaecological } \\
\text { complication }\end{array}$ & N & $\%$ \\
\hline Nil & 66 & 82.5 \\
\hline PCOS & 9 & 11.25 \\
\hline Fibroid & 3 & 3.75 \\
\hline Polyp & 1 & 1.25 \\
\hline Neoplasm & 1 & 1.25 \\
\hline
\end{tabular}

Table 3: Morphological and histopathological pattern of endometrium of patients with primary infertility.

\begin{tabular}{|lll|}
\hline $\begin{array}{l}\text { Morphological and histopathological } \\
\text { pattern of endometrium }\end{array}$ & N & $\%$ \\
\hline Anovulatory (proliferative) & 24 & 55 \\
\hline Simple hyperplasia & 12 & 15 \\
\hline Deficient secretory phase & 26 & 32.5 \\
\hline Adequate secretory phase & 18 & 20 \\
\hline Endometrial tuberculosis & 2 & 2.5 \\
\hline Arias Stella reaction & 1 & 1.25 \\
\hline Neoplastic changes & 1 & 1.25 \\
\hline
\end{tabular}

\section{DISCUSSION}

Infertility is a human concern worldwide and it has great impact on social and mental health individual. Appropriate diagnosis is essential for proper treatment plan. ${ }^{9}$ The histological examination of the endometrial biopsy is the most reliable parameter for evaluating the cause of infertility. ${ }^{10,11}$ Present study has been designed with an objective to categorize and evaluate the histopathological features of endometrium in primary infertility.

Regarding clinicodemographic profile we gave observed that mean age of patients with primary infertility was $25.76 \pm 3.21 \mathrm{yrs}$ and most of the patients were between 26 to 35 years of age. Adamson et al has reported that the mean age of the women was 25.9 years (range: 16-30 years).

This finding supports our study. ${ }^{12}$ Katole et al has reported that the majority of the women $(39.3 \%)$ belonged to 25-9 years of age group, corroborates with our study. ${ }^{13}$ Regular menstrual cycle was present in 54 $(67.5 \%)$ patients and $32.5 \%$ patients were presented with irregular cycle. Sasaki et al has reported that among the 199 patients who reported having regular menstrual cycles, 113 had proven ovulation upon ultrasound monitoring and 86 patients did not ovulate. Among the 29 patients who reported irregular cycles, 24 did not ovulate at the cycle monitoring supports our study. ${ }^{14}$

Oligohydramnios was common than polymenorrhagia and menorrhagia. This finding is supported by the work of Arnhold et al and Tscherne et al ${ }^{15,16}$. In present study we have observed that duration of infertility between 3 to
6 years was present in $34(42.5 \%)$ patients and 14 $(17.5 \%)$ patients have duration infertility more than 6 years. Elhussein et al has reported that the mean (SD) duration of infertility was 4.9(3.9) years supports our study. ${ }^{17}$ In our study most of the patients $(82.5 \%)$ have no gynaecological complication. PCOS was present in 9 $(11.25 \%)$ patients, fibroid was present in $3(3.75 \%)$ patients, polyp was present in $1(1.25 \%)$ patients and neoplasm was present in $1(1.25 \%)$. This finding corroborates with the work of Zhou et al. ${ }^{18}$ Secretory endometrium was present in $52.5 \%$ patients and was most common finding followed by proliferative endometrium. Nandedkar et al has reported that secretory endometrium was seen in $1,283(69.70 \%)$ cases of primary infertility and Proliferative endometrium was seen in 501 $(27.21 \%)$ cases of primary infertility this observation supports our study. ${ }^{19}$ Ahmed $\mathrm{M}$ et al has found that proliferative phase/an ovulation was the most common cause of infertility followed by secretory phase this finding does not support our study. ${ }^{20}$ Endometrial tuberculosis was present in $2.5 \%$ patients. Shaheen et al reported from his study that $534(7 \%)$ women were infertile, of which $2.43 \%$ had genital tuberculosis. This finding corroborates with our study.

\section{CONCLUSION}

Seizure From present study we can conclude that the mean age of patients with primary infertility was $25.76 \pm 3.21$ years and most of the patients were between 26 to 35 years of age. Regular menstrual cycle was present in $54(67.5 \%)$ patients and $32.5 \%$ patients were presented with irregular cycle. The duration of infertility between 3 to 6 years was present in 34 (42.5\%) patients. Secretory endometrium was present in $52.5 \%$ patients and was most common finding followed by proliferative endometrium. Endometrial tuberculosis was present in $2.5 \%$ patients.

Funding: No funding sources

Conflict of interest: None declared

Ethical approval: The study was approved by the Institutional Ethics Committee

\section{REFERENCES}

1. Strowitzki T, Germeyer A, Popovici R, von Wolff M. The human endometrium as a fertility-determining factor. Hum Reprod Update. 2006;12(5):617-30.

2. Infertility. Available at: https://www.who.int/newsroom/fact-sheets/detail/infertility. Accessed on 20 September 2021.

3. Infertility. Available at: https:/www.nhp.gov.in/ disease/reproductive-system/infertility. Accessed on 20 September 2021.

4. Sabharwal BD, Sofat R, Chander K. Endometrial pattern and its glycogen content in case of infertility. $\mathrm{J}$ Obstet Gynaecol India. 1987;37:718-21.

5. Balasch J, Fábregues F, Creus M, Vanrell JA. The usefulness of endometrial biopsy for luteal phase 
evaluation in infertility. Hum Reprod. 1992;7(7):9737.

6. Zawar MP, Deshpande NM, Gadgil PA, Mahanta AA. Histopathological study of endometrium in infertility. Indian J Pathol Microbiol. 2003;46(4):630-3.

7. Sahmay S, Oral E, Saridogan E, Senturk L, Atasu T. Endometrial biopsy findings in infertility: analysis of 12,949 cases. Int J Fertil Menopausal Stud. 1995; 40(6): 316-21.

8. Sample size for a prevalence survey, with finite population correction. Available at: http://sampsize. sourceforge.net/iface/. Accessed on 20 September 2021.

9. Purkayastha P, Sharma H. Prevalence and potential determinants of primary infertility in India: Evidence from Indian demographic health survey. Clin Epidemiol Global Health. 2021;9:162-70.

10. Dallenbalch-Hellweg G. The endometrium of infertility, A review. Pathol Res Pract. 1984;178:52737.

11. Preethi C, Soumya B, Gupta H, Nilekani A, Rajashekar K. A histomorphological pattern analysis in endometrial biopsies of infertile woman. IP Arch Cytol Histopathol Res. 2019;4(3):187-92

12. Adamson PC, Krupp K, Freeman AH, Klausner JD, Reingold AL, Madhivanan P. Prevalence \& correlates of primary infertility among young women in Mysore, India. Indian J Med Res. 2011;134(4):440-6.

13. Katole A, Saoji AV. Prevalence of primary infertility and its associated risk factors in urban population of central india: a community-based cross-sectional study. Indian J Commun Med. 2019;44(4):337-341.

14. Sasaki RS, Approbato MS, Maia MC, Fleury EA, Giviziez CR, Zanluchi N. Patients' auto report of regularity of their menstrual cycles. Medical history is very reliable to predict ovulation. A cross-sectional study. JBRA Assist Reprod. 2016;20(3):118-22.

15. Arnhold IJ, Latronico AC, Batista MC, Mendonca BB. Menstrual disorders and infertility caused by inactivating mutations of the luteinizing hormone receptor gene. Fertil Steril. 1999;71(4):597-601.

16. Zyklusanomalien TG. Menstrual cycle anomalies in young girls--prognosis concerning later fertility. Gynakol Geburtshilfliche Rundsch. 1998;38(1):47-9.

17. Elhussein OG, Ahmed MA, Suliman SO, Yahya LI, Adam I. Epidemiology of infertility and characteristics of infertile couples requesting assisted reproduction in a low-resource setting in Africa, Sudan. Fertil Res Pract. 2019;5:7.

18. Zhou Z. Epidemiology of infertility in China: a population-based study. BJOG. 2018;125:432-41.

19. Nandedkar SS, Patidar E, Gada DB, Malukani K, Munjal K, Varma A. Histomorphological Patterns of Endometrium in Infertility. J Obstet Gynaecol India. 2015;65(5):328-34.

20. Ahmed Ma, Afroze NB, Sabiha M. Histopathological study of endometrium in infertility: experience in a tertiary level hospital. Birdem Med J. 2012;8(2):45-9.

21. Shaheen R, Subhan F, Tahir F. Epidemiology of genital tuberculosis in infertile population. J Pak Med Assoc. 2006;56(7):306-9.

Cite this article as: Annapurna P, Pattnaik N. Evaluation of histopathology of endometrium in primary infertile women, a prospective five years observational study in Konaseema region of Andhra Pradesh. Int J Reprod Contracept Obstet Gynecol 2022;11:839-43. 